\title{
Natural in utero infection of neonatal calves with bovine viral diarrhoea virus on a large dairy farm in Saudi Arabia
}

\begin{abstract}
Authors:
Eltayb M. Abuelzein ${ }^{1}$

Mofeed A. Al-Khaliyfa ${ }^{2}$

Ahmed A. Gameel ${ }^{3}$

Affiliations:
${ }^{1}$ King Fahad Medical
Research Centre, King
Abdulaziz University, Saudi
Arabia
\end{abstract}

${ }^{2}$ Almarai Company, Riyadh, Saudi Arabia

${ }^{3}$ Faculty of Veterinary Medicine, University of Khartoum, Sudan

\section{Correspondence to:}

Eltayb Abuelzein

Email:

eabuelzein@yahoo.com

\section{Postal address:}

PO Box 80216, Jeddah 21589,

Saudi Arabia

Dates:

Received: 24 Jan. 2011

Accepted: 04 Aug. 2011

Published: 09 Nov. 2011

How to cite this article: Abuelzein, E.M., Al-Khaliyfa, M.J. \& Gameel, A.A., 2011, 'Natural in utero infection of neonatal calves with bovine viral diarrhoea virus on a large dairy farm in Saudi Arabia', Onderstepoort Journal of Veterinary Research 78(1), Art. \#318, 4 pages. http://dx.doi. org/10.4102/ojvr.v78i1.318

(C) 2011. The Authors Licensee: AOSIS OpenJournals. This work is licensed under the Creative Commons Attribution License.
The dairy industry is a large and important business in Saudi Arabia. Although farms are administered to high international standards, some reproduction problems, of uncertain aetiology, are encountered. The most frequently seen are conception failures, abortions, stillbirths and the birth of weak or malformed calves. These conditions are suggestive of bovine viral diarrhoea virus (BVDV) infection. Unfortunately, very little published information is available regarding the impact of this disease on cattle populations in Saudi Arabia. As a consequence, the present study was carried out and is the first of its kind in Saudi Arabia and the Gulf region. The aim of the study was to elucidate the role of in utero BVDV infection leading to the birth of weak or malformed calves on a large dairy farm in Saudi Arabia. The study was divided into two parts. Firstly, apparently healthy neonatal calves were sampled for the detection of pre-colostral serum antibodies to BVDV. The presence of these antibodies indicates exposure of the foetus to BVDV during the last two trimesters of gestation. Secondly, tissue samples from malformed neonatal calves were examined for the presence of BVDV antigens. Detection of such antigens confirms exposure of the foetus to the virus during the first trimester of gestation. The results of the investigation indicated that $36.1 \%$ of the neonatal calves were exposed to BVDV infection in utero. This is higher than what has been reported in the literature and suggests that dairy farmers in the Arabian Peninsula need to be made aware of the dangers of BVDV infections in their herds. The epidemiological significance of the results is discussed.

\section{Introduction}

Bovine viral diarrhoea (BVD) (Olafson, MacCallum \& Fox 1946) is caused by bovine viral diarrhoea virus (BVDV), a Pestivirus of the family Flaviviridae. This disease has long been a scourge to dairy and other cattle populations in the world (World Organization for Animal Health 2008). Cattle of all ages are susceptible and infection can be acquired in utero. Embryos and foetuses so infected may exhibit a range of clinical signs, including death, and infection can also lead to the birth of persistently infected (PI) calves (Grooms 2004). Therefore, BVDV infection can have major implications for the cattle industry (Kampa 2006; Lindberg 2002).

Massive economical losses are attributed to BVDV infection in the dairy industry worldwide (Heur, Healy \& Zerbini 2007). In developed countries, the impact of BVD on the cattle industry has been well documented (Kampa 2006; Lindberg 2002). Unfortunately, in most developing countries, the economical losses due to BVD have not been studied, despite the presence of substantial dairy industries. This is also the situation in Saudi Arabia.

The harsh and arid ecosystems in Saudi Arabia are generally unsuitable for raising cattle. However, being an affluent country, Saudi Arabia has succeeded in establishing big dairy farms that supply both local markets and other Gulf States with milk and dairy products. Cattle on these farms are mainly imported Holstein Friesians. However, some Holstein Friesians are bred locally by artificial insemination, using imported semen. Many of these dairy farms experience reproduction problems of uncertain aetiology, including gynaecological problems such as conception failures, abortions, stillbirths and malformations of neonatal calves, which are suggestive of BVDV infection. Despite this situation, little published information is available regarding BVD in the country. The present study is the first of its kind in the region. It was designed to investigate in utero exposure of foetuses to BVDV by means of detecting BVDV antigens in the tissues of malformed neonatal calves and pre-colostral antibodies to BVDV in the serum of apparently healthy calves.

The presence of BVDV antigens in the tissues of malformed calves would indicate their exposure to the virus during the first trimester of gestation (Kampa 2006), a time when their immune 
systems are incompetent and thus tolerant to the infection. The presence of pre-colostral serum antibodies to BVDV in neonates indicates foetal infection during the last two trimesters of gestation, by which time the immune system can produce specific antibodies in response to infection (Graham 2001; Moening \& Liess 1995).

\section{Materials and methods}

The farm studied was established at Al-Kharj oasis $(150 \mathrm{~km}$ south of Riyadh, Saudi Arabia) in 1977. It was developed according to international standards and is managed by qualified personnel.

There are 15000 Holstein Friesian milk cows on the farm, which have been imported as in-calf heifers. According to the farm authorities they were imported from BVDV-free herds and were tested prior to importation for the presence of BVDV. A few cows were bred locally following artificial insemination using imported semen, which, according to the farm administration, was also tested for the presence of BVDV.

The cows are zero grazed and are completely isolated from other animals from which they can contract infection. They are fed with total mixed rations and milked four times a day at six-hourly intervals.

The Holstein Friesian breed is adapted to temperate geographical zones. Therefore, to harness their full genetic potential in the harsh and hot Saudi Arabian climate, special consideration was given to their housing on the farm. The cows are housed in a semi-closed system with some degree of free movement. Cooling is maintained by large fans and cool water sprays that produce a fine mist. These cooling conditions greatly reduce the heat stress on the cows.

Each cow house on the farm can accommodate 239 milk cows. The dimensions are $160 \mathrm{~m} \times 43 \mathrm{~m} \times 6.5 \mathrm{~m}$ (length $\mathrm{x}$ width $x$ height). Each house comprises a shaded area for the day and a non-shaded area for the night and contains locking stanchions and drinkers. The feeders are in a line along the house. Lights are switched on from 18:00 to 06:00. The floors are cleaned while the cows are being milked.

The farm also has a veterinary clinic, isolation and quarantine units, a colostrum area and an incinerator.

The BVD vaccination schedule used on the farm is such that heifer calves are vaccinated at the age of 56 days. Maiden heifers are vaccinated at the age of 13 months and in-calf heifers and dry cows are vaccinated 21 days before calving. According to the farm administration only live BVDV vaccine is used on this farm.

For the study of pre-colostral serum antibodies, individual blood samples were collected from 284 apparently healthy neonatal calves (133 bull calves; 151 heifer calves) before colostrum feeding, using vacutainers and following standard methods of serum separation (OIE 2008). Sera were collected over a period of four weeks. The sera were inactivated by heating at $56{ }^{\circ} \mathrm{C}$ for $30 \mathrm{~min}$ and then stored at $-20{ }^{\circ} \mathrm{C}$ until use (2-3 weeks).

An enzyme-linked immunosorbent assay (ELISA) (Bio-X Diagnostics, Jemelle, Belgium) was used to detect antibodies in the pre-colostral sera using 96-well ELISA plates. The plates provided by the manufacturers were presensitised by monoclonal antibodies to which the BVDV was reacted and were thus ready to receive the test sera. All assay procedures were as described by the manufacturer. A volume of 0.05 $\mathrm{mL}$ of each reactant was used per well. The incubation temperature was set at $37^{\circ} \mathrm{C}$, except for that of the substrate, which was at room temperature $\left(24^{\circ} \mathrm{C}-26^{\circ} \mathrm{C}\right)$. Washing was carried out automatically by filling the wells and aspirating the washing buffer three times. Briefly, the test procedure was as follows:

- The test sera were diluted 1:100 in the dilution buffer and added in duplicate wells. Positive and negative control sera were included in the test. The plates were then incubated for $1 \mathrm{~h}$ and washed.

- A peroxidase-labelled antibovine IgG monoclonal antibody was added to each well at the dilution recommended by the manufacturers. The plates were incubated for $1 \mathrm{~h}$ and washed.

- The enzyme substrate (hydrogen peroxide) and chromogen tetramethylbenzidine were added to each well, followed by incubating the plates for $10 \mathrm{~min}$ in the dark.

- The stop solution was added to each well and the reaction was read at $450 \mathrm{~nm}$ in an ELISA plate reader and the optical density (OD) readings were recorded.

For interpretation of the results the mean OD value of the negatives was subtracted from the mean of the positive ones. The signal read for each serum sample was divided by the signal of the positive serum and multiplied by 100 to express it as a percentage. The degree of positivity (from $1+$ to $5+$ ) for each test serum was determined using a quality control table provided with the kit.

A total of 346 tissue samples were collected from 62 euthanized malformed neonatal calves for the detection of BVDV antigens. The samples included tissue from the brain, the spinal cord, the spleen, the liver, the lungs, mesenteric lymph nodes, the kidneys, the ovaries and the abomasums, as well as some cerebrospinal fluid. Each sample was placed in a sterile container and put in an ice box for immediate transport to the laboratory. The samples were stored at $-86^{\circ} \mathrm{C}$ until tested with an antigen-capture ELISA (usually within two weeks of sample collection).

An antigen-capture ELISA designed to detect BVDV antigens in tissues (IDEXX Herschel, IDEXX Laboratories, Schiphol-Rijk, The Netherlands) was performed according to the manufacturer's instructions. The procedure included preparing the tissues, performing the test, and collecting and interpreting the results. All reagents and plates were 
provided as part of the kit. Reactant volumes, incubation times, the washing procedure and result collection were as described earlier. Briefly, the test procedure was as follows:

- Ready-for-use microtitre ELISA plates with immobilised monoclonal antibodies specific to BVDV were provided in the kit.

- The tissue sample suspected to contain BVDV antigen was added to sensitised plates. Following incubation and washing, the plates received the conjugate, which consisted of the specific antibody to BVDV conjugated to horseradish peroxidase. The plates were again incubated and washed.

- The substrate solution was added. In the presence of the peroxidase enzyme the substrate is converted into a product which reacts with chromogen to generate a blue colour.

Interpretation of the results was performed according to the formula

${ }_{P}^{S}=\frac{\overline{O D}_{\text {sample }}-\overline{O D}_{\mathrm{nc}}}{\overline{O D}_{\mathrm{pc}}-\overline{O D}_{\mathrm{nc}}}$

where $O D_{\text {sample }} O D_{\mathrm{nc}}$ and $O D_{\mathrm{pc}}$ denote the optical density readings of the sample, the negative control and the positive control, respectively. Samples for which S:P $\leq 0.20$ were classified as negative, whilst those for which $\mathrm{S}: \mathrm{P} \leq 0.30$ were classified as positive.

\section{Ethical consideration}

All the ethical considerations regarding this manuscript were taken into account.

\section{Results}

Table 1 shows the results of the ELISA for antibodies in the pre-colostral sera. Of the 284 serum samples tested, 76 (26.8\%) contained antibodies against BVDV. Positive reactions were seen in $27.8 \%$ of the samples from the bull calves and in $25.8 \%$ of the samples from the heifer calves.

According to the manufacturer's criteria, positive serum reactions can be graded from weak (+) to very strong (5+). A value of $3+$ is regarded as indicative of a strong reaction. Figure 1 shows the distribution of reaction strengths in precolostral sera. Of the positive serum samples, 5.5\% were weakly positive (+), $16.2 \%$ showed a slightly stronger reaction $(2+)$, and $78.3 \%$ showed a strong reaction $(43.2 \%$ scored $3+$; $35.1 \%$ scored $4+$ ). No samples showed a very strong reaction $(5+)$, as defined by the manufacturer.

BVDV antigen was detected in tissue samples of 49 (79\%) malformed neonatal calves. Table 2 summarises the corresponding ELISA results.

Table 3 shows the total number of neonatal calves that were exposed to BVDV infection in utero (i.e. malformed calves that tested positive for BVDV antigen as well as calves displaying pre-colostral antibodies to BVDV).

\section{Discussion}

Results of the study showed that $26.8 \%$ of the calves examined had developed pre-colostral antibodies to BVDV and that both sexes were affected to almost the same extent. This indicates that these calves had been infected in utero during either the second or the last trimester of gestation. At that age the immune system of the foetus is capable of responding to the BVDV infection by producing antibodies. The results also indicated that $78.3 \%$ of the positive sera yielded strong reactions. Compared to those of other published reports, the result of $26.8 \%$ positive reactions in pre-colostral serum suggests that infection in this particular herd is three to four times higher than elsewhere (see for example Schefers et al. 2008 for US results). This is not surprising, as no strict control

TABLE 1: Detection of pre-colostral antibodies against bovine viral diarrhoea virus in neonatal calves' sera.

\begin{tabular}{llcc}
\hline Animals tested & Number tested & \multicolumn{2}{c}{ Positive samples } \\
\cline { 3 - 4 } & & Number & $\mathbf{\%}$ \\
\hline Bull calves & 133 & 37 & 27.8 \\
Heifer calves & 151 & 39 & 25.8 \\
\hline Total & $\mathbf{2 8 4}$ & $\mathbf{7 6}$ & $\mathbf{2 6 . 8}$ \\
\hline
\end{tabular}

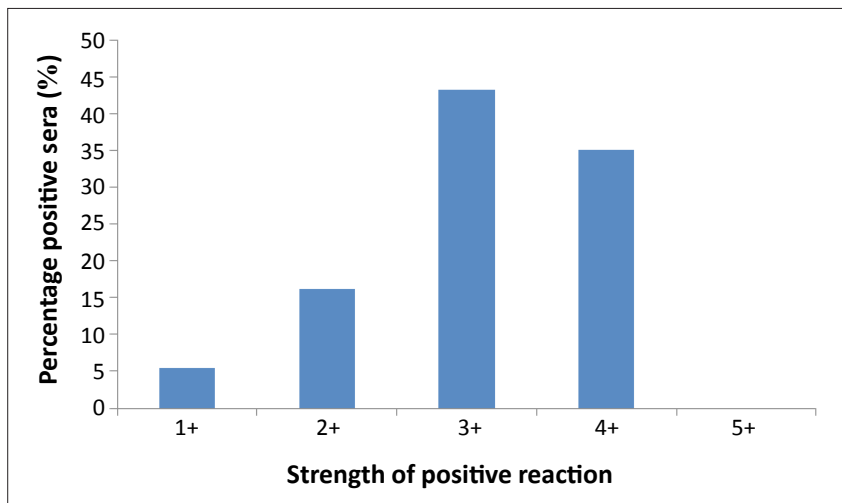

FIGURE 1: Distribution of reaction strengths obtained from positive pre-colostral sera.

TABLE 2: Positive antigen detections in tissues from malformed neonatal calves.

\begin{tabular}{llcc}
\hline Sampled tissue & \multirow{2}{*}{ Number tested } & \multicolumn{2}{c}{ Positive samples } \\
\cline { 2 - 4 } & & Number & $\mathbf{\%}$ \\
\hline Kidney & 49 & 43 & 87.8 \\
Liver & 60 & 51 & 85.0 \\
Spleen & 62 & 38 & 61.3 \\
Ovary & 4 & 2 & 50.0 \\
Abomasum & 6 & 3 & 50.0 \\
Brain & 51 & 22 & 43.1 \\
Mesenteric lymph nodes & 35 & 8 & 22.9 \\
Spinal cord & 9 & 2 & 22.2 \\
Cerebrospinal fluid & 22 & 4 & 18.2 \\
Lungs & 48 & 4 & 8.3 \\
\hline Total & $\mathbf{3 4 6}$ & $\mathbf{1 7 7}$ & $\mathbf{5 1 . 2}$ \\
\hline
\end{tabular}

TABLE 3: Summary of exposure of neonate calves to bovine viral diarrhoea virus infection in utero.

\begin{tabular}{llcc}
\hline Response to infection & Number tested & \multicolumn{2}{c}{ Positive samples } \\
\cline { 3 - 4 } & & Number & $\mathbf{\%}$ \\
\hline Malformation & 62 & 49 & 79.0 \\
$\begin{array}{l}\text { Presence of pre-colostral } \\
\text { serum antibodies }\end{array}$ & 284 & 76 & 26.8 \\
\hline Total & $\mathbf{3 4 6}$ & $\mathbf{1 2 5}$ & $\mathbf{3 6 . 1}$ \\
\hline
\end{tabular}


policy for BVD, other than vaccination, was implemented on this particular farm. Vaccination alone seemed to have little beneficial effect and should therefore preferably be combined with other control measures, for example removal of PI animals.

Furthermore, the BVDV antigen was detected in all types of the tissue sampled, albeit at different rates. This indicates that the virus was pantropic in its distribution in the foetal tissues. This is not unexpected, as the malformed calves were immunotolerant at the age when they were exposed to the BVDV (during the first trimester of gestation). In addition, BVDV is known to show a high affinity towards rapidly dividing cells, which makes foetal tissues favoured sites for virus replication (Cornish, Van Olphen \& Cavender 2005; Duffell \& Harkness 1985).

Our overall results showed a high level of detection frequency (51.2\%) of the BVDV antigen in tissues of the malformed calves. However, the incidence rate ranged from $8.3 \%$ (lungs) to $87.8 \%$ (kidneys). The highest incidences were seen in the kidneys (87.8\%), livers (85\%) and spleens (61.3\%). The results may be attributed to the excretion of the virus and immune complexes via the kidneys and the liver. It is also the case that BVDV is often associated with macrophages and other immune-competent cells present in the spleen. Moreover, the stationary macrophages, such as the mesangial cells in the kidney and the Kupffer cells in the liver, can trap the BVDV. Such trapping would be expected to add to the virus load in these organs.

The observation of both malformed calves and calves presenting with pre-colostral antibodies to BVDV suggests that the dams were subjected to BVDV infection throughout their pregnancies. This indicates continuous circulation of the virus on the farm and probably the presence of PI animals (Alkhaliyfa, Abuelzein \& Gameel 2010). Indeed, the dams themselves could have been PI animals (Lindberg 2002). It is also possibile that the semen used for artificial insemination on this farm might have contained BVDV and it is recommended that this potential source be tested for the presence of the virus.

Published information suggests that the most important sources of BVDV infection within and between dairy cattle herds are PI animals (Lindberg 2002). PI animals therefore constitute a continuous and major threat to dairy cattle. It is recommended that the identification of PI animals should be a pre-requisite to planning control measures against BVD in a particular geographical region, whether BVDV is endemic or not (Duffell \& Harkness 1985; Fredriksen, Sandvik \& Loken 1999; Ridpath, Hessman \& Neill 2006).

The overall results of the present investigation showed that $36.1 \%$ of the neonatal calves tested on this farm were infected by BVDV in utero. The malformed calves had to be euthanised. In view of this high incidence we recommend that an urgent assessment of the economic damage caused by these annual losses should be carried out.

\section{Conclusion}

We recommend that dairy farms in Saudi Arabia should adopt a policy of regular testing for the presence of animals persistently infected with BVDV and subsequent removal of such animals. The low efficacy of the adopted vaccine regimen on this particular test farm warrants its re-evaluation. It is vital that farmers be made aware of the high financial costs associated with BVDV infection.

\section{Acknowledgements}

The authors gratefully acknowledge the kind assistance of staff members on the farm. The authors would also like to thank Prof. P.S. Mellor for his valuable comments.

\section{Author contributions}

E.M.A. is the principal investigator who planned this work, supervised the research process (Field and Laboratory investigations) and wrote the manuscript. M.A.A. conducted the clinical work, collected the materials and was involved in the laboratory work. A.A.G. was involved in the identification of the different types of malformations in the neonate calves and supervised the sampling from the malformed calves. All the authors participated in brain storming discussions that involved the research work and the manuscript.

\section{References}

Alkhaliyfa, M.A., Abuelzein, E.M.E. \& Gameel, A.A., 2010, 'Identification of cattle persistently infected with BVDV by ear-notch testing in Saudi Arabia', Veterinary Record 167, 660-661.

Cornish, T.E., Van Olphen, L.A. \& Cavender, J.L., 2005, 'Comparison of ear notch immunohistochemistry, ear notch antigen-capture ELISA, and buffy coat virus immunohistochemistry, ear notch antigen-capture ELISA, and buffy coat virus
isolation for detection of calves persistently infected with bovine viral diarrhea isolation for detection of calves persistently infected with bovine viral diarrhea org/10.1177/104063870501700203, PMid: 15825490

Duffell, S.J. \& Harkness, J.W., 1985, 'Bovine virus diarrhoea-mucosal disease infection in cattle', Veterinary Record 117, 240-245. http://dx.doi.org/10.1136/ vr.117.10.240, PMid: 4095876

Fredriksen, B., Sandvik, T. \& Loken, T., 1999, 'Level and duration of serum antibodies in cattle infected experimentally and naturally with bovine virus diarrhoea virus' Veterinary Record 144, 111-114. http://dx.doi.org/10.1136/vr.144.5.111, PMid: 10070699

Graham, D.A., 2001, 'Bovine viral diarrhoea virus (BVDV) on cattle farms: disease and control', Cattle Practitioner 9, 111-118.

Grooms, D.L., 2004, 'Reproductive consequences of infection with bovine vira diarrhoea virus', Veterinary Clinics of North America: Food Animal Practice 20 5-19. http://dx.doi.org/10.1016/j.cvfa.2003.11.006, PMid: 15062471

Heur, C., Healy, A. \& Zerbini, C., 2007, 'Economic effects of exposure to bovine viral diarrhoea virus on dairy herds in New Zealand', Journal of Dairy Science 90(12), 5428-5438. http://dx.doi.org/10.3168/jds.2007-0258, PMid: 18024733

Kampa, J., 2006, 'Epidemiology of bovine virus diarrhea virus and bovine herpesvirus type 1 infection in dairy cattle herds', PhD thesis, Dept. of Clinical Sciences, Swedish University of Agricultural Sciences.

Lindberg, A., 2002, 'Epidemiology and eradication of bovine viral diarrhea virus infection', PhD thesis, Dept. of Ruminant Medicine and Veterinary Epidemiology, Swedish University of Agricultural Sciences.

Moening, V. \& Liess, B., 1995, 'Pathogenesis of intrauterine infections with bovine viral diarrhoea virus', Veterinary Clinics of North America: Food Animal Practice $11,477-487$.

OIE. See World Organization for Animal Health.

Olafson, P., MacCallum, A.D. \& Fox, F.H., 1946, 'An apparently new transmissible disease of cattle', Cornell Veterinary 36, 205-213.

Ridpath, J.F., Hessman, B.E. \& Neill, J.D., 2006, 'Parameters of ear notch samples for BVDV testing: stability, size requirements and viral load', Proceedings of the 39th Annual Conference of the American Association of Bovine Practitioners, Saint Paul, Minnesota, USA, September 21-23, 2006, pp. 269-270.

Schefers, J., Munoz-Zanzi, C., Collins, J.E., Goyal, S.M. \& Ames, T.R., 2008, 'Serological evaluation of pre-colostral serum samples to detect bovine viral diarrhoea virus infections in large commercial dairy herds', Journal of Veterinary Diagnostic Investigation 20, 625-628. http://dx.doi.org/10.1177/104063870802000515, PMid:18776097

World Organization for Animal Health, 2008, 'Bovine viral diarrhoea', in Manual of Diagnostic Tests \& Vaccines for Terrestrial Animals: Mammals, Birds \& Bees, 6th edn., Vol.2, pp. 698-711, OIE Publications, Paris. 